\title{
Synthesis of Carboxymethyl Chitosan and its Rheological Behaviour in Pharmaceutical and Cosmetic Emulsions
}

\author{
Desislava Tzaneva ${ }^{1}$, Apostol Simitchiev $^{2}$, Nadezhda Petkova $^{1 *}$, Ventzislav Nenov $^{2}$, Albena Stoyanova ${ }^{3}$, Panteley Denev $^{1}$ \\ ${ }^{1}$ Department of Organic Chemistry, University of Food Technologies, 26 Maritza Blvd., 4002, Plovdiv, Bulgaria. \\ ${ }^{2}$ Department of Machinery for Food Industry, Technical Faculty, University of Food Technologies, 26 Maritza Blvd., 4002, Plovdiv, Bulgaria. \\ ${ }^{3}$ Department of Essential Oils, University of Food Technologies, 26 Maritza Blvd., 4002, Plovdiv, Bulgaria.
}

\begin{tabular}{l} 
ARTICLE INFO \\
\hline Article history: \\
Received on: $28 / 06 / 2017$ \\
Accepted on: $15 / 09 / 2017$ \\
Available online: $30 / 10 / 2017$ \\
\hline Key words: \\
Carboxymethyl chitosan, \\
FTIR spectroscopy, NMR \\
spectra, TGA, emulsions, \\
rheological and \\
thermodynamic properties.
\end{tabular}

\section{INTRODUCTION}

Chitin is the secondmost abundant and renewable polysaccharide in nature only after cellulose (Kasaai et al., 2013). Its chemical structure is similar to cellulose: both polysaccharides have $\beta$ - $(1 \rightarrow 4)$ glycosidic linkages and they are able to form intermolecular hydrogen bonds. Chitin is highly crystalline and insoluble in common solvents. It isoften converted into chitosan by deacetylation. The word "chitosan" is used for both partially and completely $\mathrm{N}$-deacetylated chitins. Commercial chitin and chitosan are copolymers of 2-acetamido2-deoxy-D-glucose (GlcNAc) and 2-amino-2-deoxy-D-glucose

\footnotetext{
* Corresponding Author

Nadezhda Petkova, Department of Organic Chemistry, University of Food Technologies, 26 Maritza Blvd., 4002, Plovdiv, Bulgaria.E-mail: petkovanadejda@abv.bg
}

$(\mathrm{GlcN})$ with $\beta$-D-( $1 \rightarrow 4)$ glycoside linkages. The chemical structures of cellulose, chitin and chitosan are illustrated (Fig. 1).

"Green chemistry" with its part of biomaterials using natural polymers is developed with significant steps in and forms a promising field of research (Sharma et al., 2017). Chitosan is an inexpensive and renewable material with many applications in cosmetics, pharmaceuticals, food science and biotechnology (Kim et al., 2003; Lei et al., 2003).

Due to the poor solubility of chitosan (only in acidic aqueous solutions below pH 6.5) its application is limited in many fields where solubility is a prime factor. The solubility of chitosan can be improved by depolymerization and its chemical modifications (Cravotto et al., 2005). Chitosan contains reactive amino, primary and secondary alcohol groups that can be object of chemical modifications under mild reaction conditions to alter its properties (Mourya and Inamdar, 2008; Shanmuganathan et al., 2016). 

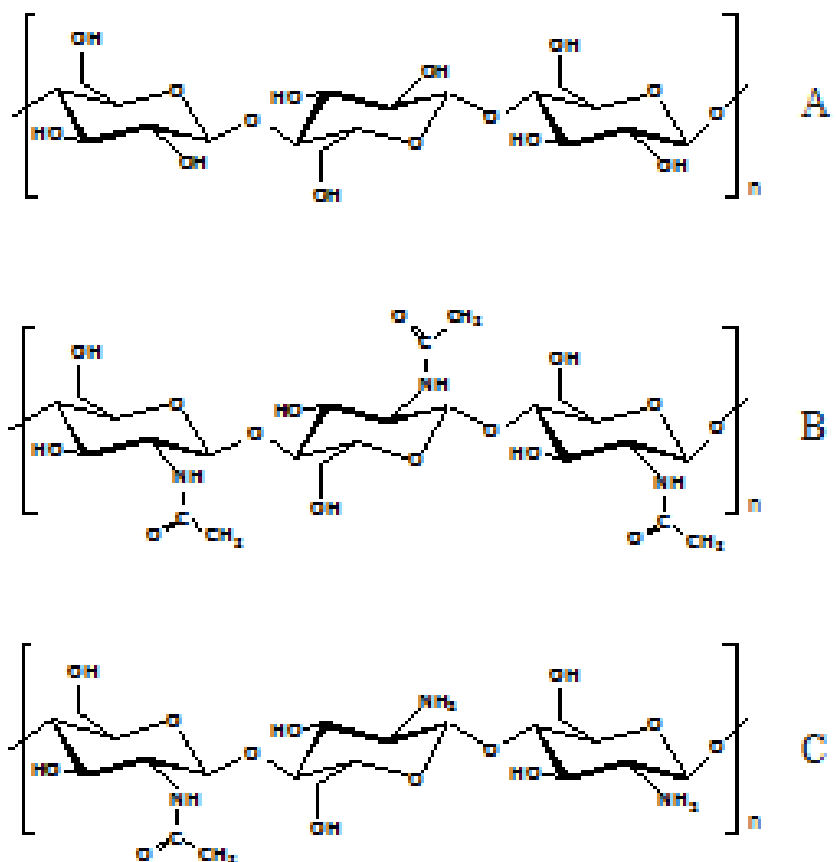

Fig. 1: Chemical structuresof some polysaccharides: cellulose (A), chitin (B) andchitosan (C)

Many water-soluble derivatives have been prepared by quaternarization (Jia et al., 2001; Mourya and Inamdar, 2009) or by introducing hydrophilic groups like hydroxypropyl, dihydroxyethyl, hydroxyalkylamino (Jung et al. 1999; Kurita, 2001; Sashiwa et al., 2003), sulfate (Holme and Perlin, 1997); phosphate, carboxyalkyl groups as carboxymethyl, carboxyethyl, carboxybutyl or by grafting water-soluble polymer (Yalpani et al., 1991; Ouchi et al., 1998; Park et al., 2003;Mourya et al., 2010) in the macromolecular chain of chitosan. Compared with other watersoluble chitosan derivatives, CMC has attracted much attention and has been widely studied because of its ease of synthesis, water solubility, ampholytic character and possibilities of wide range of application fields.

Carboxymethyl chitosan possesses not only a good solubility in water, but also has unique chemical, physical and biological properties such as high viscosity, large hydrodynamic volume, low toxicity, biocompatibility and good ability to form films, fibers and hydrogels (Muzzarelli, 1988; Chen et al., 2005). The CMC can be in form of O-CMC, N-CMC and N,O-CMC (Mourya et al., 2010). The properties and applications of CMC strongly depends on its structural characteristics, mainly the average degree of substitution and the position of the carboxymethylation (grafting to amino orhydroxyl groups)(de Abreu and Campana-Filho, 2005).

In recent years, the cosmetic industry has been a rapidly growing industry worldwide (Lee et al., 2013). Continuous development of new active ingredients for cosmetics and personal care products is one of the most important areas of research in this industry (Cochran and Brockman 2007; Yang et al., 2011). As a result, there are a significant number of novel cosmetic products that are based on a new generation of active ingredients (Patravale and Mandawgade, 2008). Therefore, the potential applications of CMC in cosmetics will be viewed into five major uses as: moisture absorption-retention agent, anti-microbial agent, antioxidant agent, delivery system and oil/water emulsions stabilization (Ali et al., 2013; Jimtaisong and Seawan, 2014).

The current study is focused on synthesis and characterization of CMC and further evaluation of its emulsion stabilizing properties for preparation of cosmetic and pharmaceutical emulsions.

\section{MATERIALS AND METHODS}

Chitosan (molecular weight of $100-300 \mathrm{kDa}$ ) was purchased from Acros Organics (Belgium). Other chemicals and solvents (chloroacetic acid, sodium hydroxide, 2-propanol and methanol) were of analytical grade and were used without further purification.

\section{Characterization of chitosan \\ Degree of deacetylation}

The degree of deacetylation was determined by conductometric titration (Ewing, 1969). In brief, the chitosan sample $(500 \mathrm{mg}$ ) was stirred in $150 \mathrm{~mL} 0.5 \mathrm{M}$ hydrochloric acid at room temperature until completely dissolved and titrated with 0.5 M sodium hydroxyde at $25^{\circ} \mathrm{C}$. Sodium hydroxide solution was added in portions of $0.2 \mathrm{~mL}$ in interval of $20 \mathrm{~s}$ added in portions of $0.2 \mathrm{mLin}$ interval of $20 \mathrm{~s}$. The values of conductance $\left(\mathrm{mS}^{\mathrm{c}} \mathrm{cm}^{-1}\right)$ with the corresponding titrant volumes were plotted in a graphic to find the linear variation before and after the equivalence point. The degree ofdeacetylation (DD) was calculated using the following equation (1):

$$
D D=\frac{[\text { base }]\left(V_{2}-V_{1}\right) 161}{m}
$$

where [base] is the concentration of the sodium hydroxide solution; $\mathrm{V}_{1}$ and $\mathrm{V}_{2}$ are the volumes of sodium hydroxide $(\mathrm{mL})$ used in the titration in two inflection points; 161 is the molar mass of the glucosamine monomer $\left(\mathrm{C}_{6} \mathrm{H}_{11} \mathrm{O}_{4} \mathrm{~N}\right)$ and $m$ is the mass of chitosan (mg).

\section{Synthesis of CMC}

Synthesis of CMC was prepared from chitosan as described previously (Chen and Park, 2003; Miao et al., 2006; Bidgoli et al., 2010). Briefly, chitosan (2 g) suspended in $50 \%$ $(\mathrm{w} / \mathrm{v})$ sodium hydroxide $(20 \mathrm{~mL})$ was left swelling for $1 \mathrm{~h}$ at room temperature and kept at $-20{ }^{\circ} \mathrm{C}$ for alkalization for $12 \mathrm{~h}$, then thawed at room temperature. The alkali chitosan was suspended into 2-propanol $(50 \mathrm{~mL})$ and the mixture was stirred on magnetic stirrer for $30 \mathrm{~min}$ and then in water bath shaker at $50{ }^{\circ} \mathrm{C}$. Chloroacetic acid $(10 \mathrm{~g})$ dissolved in isopropanol $(30 \mathrm{~mL})$ was added by drops over a period of $30 \mathrm{~min}$. The reaction mixture was stirred for $12 \mathrm{~h}$ in a water bath at $50{ }^{\circ} \mathrm{C}$. Then the liquid fraction was decanted and methanol $(100 \mathrm{~mL})$ was added to the resulting slurry. The suspension was neutralized using glacial acetic acid. 
Then the mixture was filtered and washed several times with methanol. The resulting CMC was purified by dissolving in deionized water and filtered to remove undissolved residues. The resultant solution was precipitated in addition of methanol. Finally the pure product was separated by filtration, rinsed with methanol, vacuum freeze dried and stored in a desiccator until further use.

\section{Characterization of CMC \\ Degree of substitution}

The degree of substitution of CMC was determined by potentiometric titration(Hua-Cai and Deng, 2005). CMC was dissolved in distilled water and the solution was adjusted to $\mathrm{pH}<2$ by addition of hydrochloric acid. Then, the CMC solution was titrated with $0.1 \mathrm{M}$ aqueous sodium hydroxide and the $\mathrm{pH}$ value of the solution was simultaneously recorded. The amount of aqueous sodium hydroxide was determined by the second order differential method. The degree of substitution (DS) was calculated as follows:

$\mathrm{A}=\mathrm{V}_{\text {sodium hydroxide }} \times \mathrm{c}_{\text {sodium hydroxide }}$

$$
D S=\frac{161 . A}{m_{C M C}-58 . A}
$$

where $\mathrm{V}_{\text {sodium hydroxide }}$ and $\mathrm{c}_{\text {sodium hydroxide }}$ are the volume and molarity of aqueous sodium hydroxide, respectively; $m_{C M C}$ is the mass of CMC (g), and 161 and 58 are the molecular weight of glucosamine (chitosan skeleton unit) and a carboxymethyl group, respectively (Mouryaet al., 2010).

\section{FTIR-spectroscopy}

The FTIR spectra of chitosan and the sodium salt of CMC were recorded on Nicolet Avatar 330 FT-IR, Termo Science, (USA)spectrophotometer in $\mathrm{KBr}$ pellets. The scanning range was $400-4000 \mathrm{~cm}^{-1}$ with 132 scans at $4 \mathrm{~cm}^{-1}$ resolution.

\section{NMR spectroscopy}

The ${ }^{13} \mathrm{C}$ NMR spectra of chitosan and CMC were recorded on a Brucker AVIII 500M spectrometer using polymer samples in form of sodium salts dissolved in $\mathrm{D}_{2} \mathrm{O}$ (for $\mathrm{CMC}$ )and in $\mathrm{CD}_{3} \mathrm{COOD}$ (for chitosan) at a concentration of $40 \mathrm{mg} / \mathrm{mL}$. All chemical shifts were given relative to a tetramethylsilane (TMS) as internal standard.

\section{Thermal analysis (TGA/DTA)}

The thermophysical properties of chitosan and CMC were investigated by differential thermal analysisthermogravimetric analysis (DTA-TG) using LABSY TM Sevo (Setaram, France). The DTA-TG curves were obtained during heating of the samples with a heating rate of $5{ }^{\circ} \mathrm{C} / \mathrm{min}$ from $10{ }^{\circ} \mathrm{C}$ to $400{ }^{\circ} \mathrm{C}$ under nitrogen atmosphere (Murdzheva et al., 2016).

\section{Preparation of the oil/water pharmaceutical and cosmetic emulsions}

The phase I contained the following ingredients with (INCI) names: 1. Emulgade ${ }^{\circledR}$ SE (Glyceryl Stearate (and)
Ceteareth-20 (and) Ceteareth-12 (and) Cetearyl Alcohol (and) Cetyl Palmitate $-6 \%$; 2. Lanette ${ }^{\circledR} \mathrm{O}$ (Cetearyl Alcohol) - 2\%; 3.Cera Alba - 1\%; 4.Parafinumliquidum - 6\%; 5.CaprilicCapric Triglyceride $-6.5 \%$; 6.Isopropyl Myristate - 6\%; 7.Nipagin ${ }^{\circledR}$ (Methyl paraben) $-0.2 \%$; 8.Nipasol ${ }^{\circledR}$ (Propyl paraben) $-0.1 \%$. The phase II contained: 1 . Glycerol $-4.0 \% ; 2$. Aqua - to $100 \%$. The phase III containsed: 1.Carbopol ${ }^{\circledR}$ Ultrez 21 (Carbomer) $0.30 \%$ (control - emulsion 1); CMC - $0.5 \%$ (emulsion 2) and CMC $-0.3 \%$ (emulsion` 3 ).

The phase IV contained: Triethanolamine $-0.3 \%$ (emulsion 1$)$ The phase $V$ contained: 1 . Bronopo ${ }^{\circledR}$ (2-Bromo-2-Nitropropane1,3-Diol) - 0.05\%; 2. Rosa damascena Absolute - $0.3 \%$ (perfume and active ingredient).

In all variants the phases $I$ was heated at $80-85^{\circ} \mathrm{C}$. The phase III was added into the phase II under stirring. Phase II was heated at $80-85{ }^{\circ} \mathrm{C}$ and then added to phase $I$ and the resulting mixture was homogenized with laboratory homogenizing device Polytron ${ }^{\circledR}$ PT45-80 (Kinematika, Switzerland) with technical characteristics $-1600 \mathrm{~W}, \max 250 . \mathrm{s}^{-1}$ for $2 \mathrm{~min}$. The emulsions obtained were cooled. The phase $I V$ was added into the hot emulsion $\left(60^{\circ} \mathrm{C}\right.$ for emulsion 1$)$ and homogenized. The prepared emulsions were allowed to cool with stirring in such a way that it remains in continual motion as avoiding the incorporation of air. The phase $V$ was added at $40^{\circ} \mathrm{C}$.

\section{Determination of $\mathrm{pH}$}

The acidity of the emulsions has been determined by $\mathrm{pH}$ meter Hanna HI 98127 with replaceable electrode.

\section{Determination of emulsion stability}

The long-term emulsion stability was determined by centrifuge test according to the procedure of Tcholakova et al. (2004).

\section{Microscopic Test}

The microstructure of the emulsions was investigated by microscope Olympus BX41 (USA), equipped with USB camera connected to a personal computer. The drop sizes distribution was observed at magnification $\times 1000$.

\section{Determination of emulsion turbidity}

The investigations were performed by CamspecM107 (UK) Double Beam Scaning UV/VIS spectrophotometer. Series of standard emulsion solutions were placed into a disposable spectrophotometer cuvette $(1 \mathrm{~mL})$ and the change of the emulsion turbidity were measured in a range of $375-405 \mathrm{~nm}$ (Gandova and Balev, 2016). Thermodynamic parameters (Gibbs free energy, enthalpy and entropy) of the emulsions were calculated by the equation (3):

$$
\frac{d \ln K}{d(1 / T)}=\frac{-\Delta H}{R}
$$

For Gibbs free energy and entropy determination were used the classical thermodynamic equations (4) and (5): 


$$
\begin{gathered}
\Delta G=-R T \ln K \\
\Delta S=\frac{(\Delta H-\Delta G)}{T}
\end{gathered}
$$

where $\Delta H$ - enthalpy $\left(\mathrm{kJ} \cdot \mathrm{mol}^{-1}\right), \Delta G$ - Gibbs free energy $\left(\mathrm{kJ} \cdot \mathrm{mol}^{-1}\right)$, $\Delta S$ - entropy $\left(\mathrm{kJ}^{-1} \mathrm{~K}^{-1} \cdot \mathrm{mol}^{-1}\right), R$ - universal gas constant $(R$ $\left.=8.314 \mathrm{~J} \cdot \mathrm{K}^{-1} \cdot \mathrm{mol}^{-1}\right), T-$ absolute temperature $(\mathrm{K}), K-$ equilibrium constant.

\section{Rheological behavior}

The rheological behavior of the prepared emulsions was studied on a rotary viscometer "Brookfield" RV DV-II + Pro, equipped with an adapter for small samples, comprising a metal cylinder measuring with a water jacket SC4-13R and a cylindrical spindle with conical head SC4-27 (a length of the tube $33.02 \mathrm{~mm}$ and diameter $11.76 \mathrm{~mm}$ and total length of the working part 39.29 $\mathrm{mm})$. The measuring cylinder had an internal diameter of 19.05 $\mathrm{mm}$ and a length of $64.77 \mathrm{~mm}$. The upper conical part of the spindle should cover the test product. Therefore, during each experiment, the cylinder was filled with emulsion volume of $10.4 \mathrm{~mL}$. Before the start of measurement, an insulating cap was placed on the neck of cylinder, and then began the preliminary experiments in order to specify the range of shear rates in which the measurements were possible to be done. The water jacket of the adapter for small samples was connected by flexible connections with ultra-thermostat "Zemail Horyzont", equipped with a contact thermometer with a range from 0 to $100{ }^{\circ} \mathrm{C} \pm 0.1$ and second control thermometer with the same scope. The measuring cylinder was filled with emulsion and then heated at four different temperatures $\left(20,25,30\right.$ and $35^{\circ} \mathrm{C}$, respectively) for a period of $5 \mathrm{~min}$. The selected temperatures were concerned with the storage and stability conditions of emulsions. After reaching the required temperature, an insulating cap was placed on the neck of the cylinder, and then the experiments can be started. An experiment was designed, during which the structural and mechanical properties of each emulsion were measured at 28 shear rates $\left(\mathrm{D}=0.1 \div 1.02 \mathrm{~s}^{-1}\right)$ determined during the preliminary experiments. Each experiment continued $42 \mathrm{~min}$ - the spindle rotated at every shear rates for the period of $90 \mathrm{~s}$ at the end of which the viscometer registered a reading. The resulting data were used for constructing graphical dependencies between the shear stress and the shear rate which were used to define the rheological properties of the emulsion. The average values of the results from the experiments were approximated by the rheological model of Herschel-Bulkley equation (6) which has the highest R-squared coefficients. The same file presented also graphical dependencies between shear rate and apparent viscosity and between shear rate and shear stress for the individual emulsions at all tested temperatures.

$$
\tau=\tau_{0}+k . D^{n}
$$

where $\tau$ - shear stress, Pa; $\tau_{0}$ - yield stress, Pa; $\mathrm{k}-$ consistency index, Pa. $\mathrm{s}^{\mathrm{n}} ; \mathrm{D}-$ shear rate, $\mathrm{s}^{-1} ; \mathrm{n}-$ flow index.

\section{RESULTS AND DISCUSSION}

\section{Characterization of CMC}

General reaction scheme for synthesis of CMC with monochloroacetic acid in $50 \%$ sodium hydroxide was shown (Fig. 2). The resulting yield of CMC was $2.4 \mathrm{~g}$ or $83 \%$ on the base of used chitosan. The synthesized CMC with DS $50 \%$ demonstrated good water solubility that is an important characteristic for this chitosan derivate. Our findings were in agreement of Chen $e t$ al. (2005), who recognized that the DS value in the range of 0.40 to 0.45 became CMC soluble in water. Water solubility of CMC plays significant role in application of CMC, especially for drug delivery systems and strongly depends on concentration of sodium hydroxide used in reaction conditions (Mourya et al., 2010). In our case modification of chitosan with $50 \%$ sodium hydroxide at lower temperature gave CMC with DS $50 \%$. A $50 \%$ sodium hydroxide solution seemed to provide the optimum alkali concentration in the carboxymethylation process (Mourya et al., 2010).

Our results proved that CMCs prepared at temperatures of $50{ }^{\circ} \mathrm{C}$ were soluble in water (Ali et al., 2013; Bidgoli et al., 2010; Chen and Park, 2003).Compared with chitosan, the solubility of CMC in aqueous solution could be explained with the introduction of carboxymethyl group. DS is important parameter, which could influence its performance in many of its applications. Other physicochemical parameters of CMC were summarized in Table 1.

Table 1: Comparative characteristics of chitosan and carboxymethyl chitosan

\begin{tabular}{ccc}
\hline Characteristic & Chitosan & CMC \\
\hline Appearance & fine powder & fine powder \\
Colour & pure white & pure white \\
Odour & no & no \\
Degree of deacetylation, $\%$ & 79 & - \\
Degree of substitution, $\%$ & - & 50 \\
Solubility & in acidic medium & in water \\
\hline
\end{tabular}

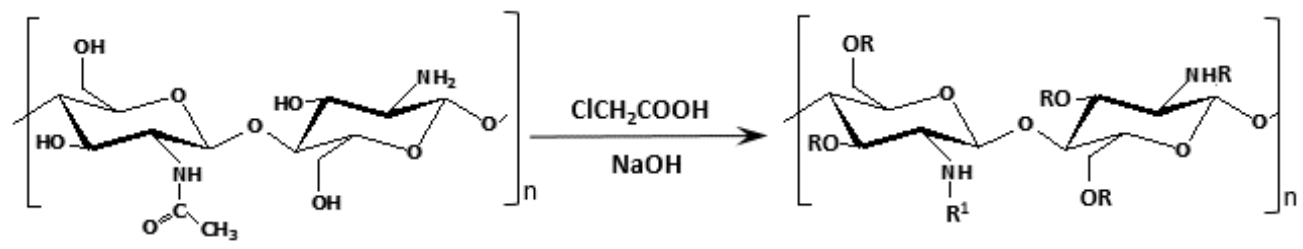

$$
\begin{aligned}
& \mathrm{R}=-\mathrm{CH}_{2} \mathrm{COONa} \text { or } \mathrm{H} \\
& \mathrm{R}^{1}=\mathrm{CH}_{3} \mathrm{CO}-\text { or } \mathrm{H}
\end{aligned}
$$

Fig. 2: General reaction scheme for synthesis of CMC. 


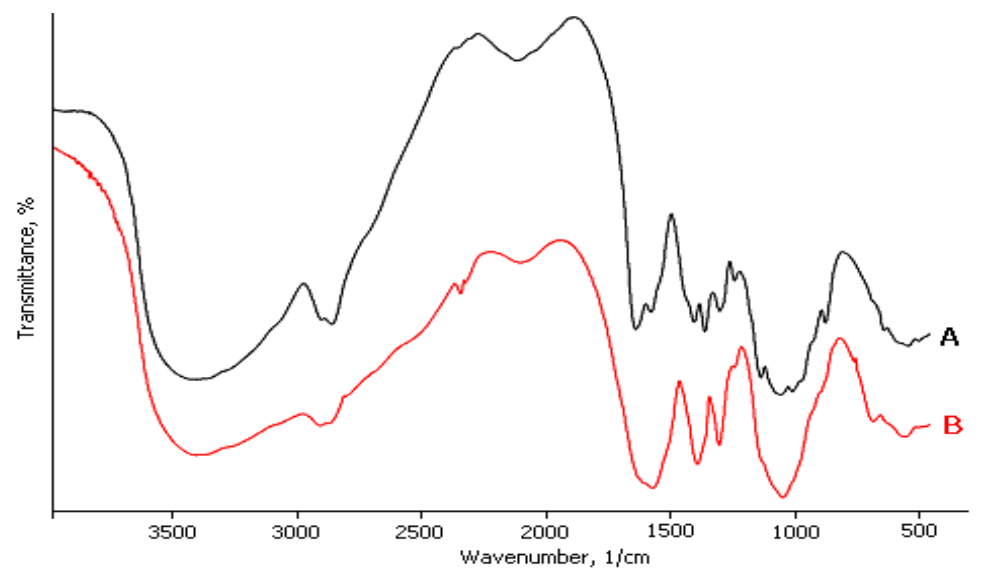

Fig. 3: FTIR - spectra of chitosan (A) and CMC (B).

\section{FTIR-spectroscopy}

The carboxymethylation provoked structural changes that were clearly identified by comparing the FTIR spectra of chitosan and CMC (Fig. 3).

As it was shown (Fig.3), both spectra showed abroad absorption band between $3500 \mathrm{~cm}^{-1}$ and $3100 \mathrm{~cm}^{-1}$, due to $\mathrm{O}-\mathrm{H}$ stretching vibrations, $\mathrm{N}-\mathrm{H}$ extension vibration and the intermolecular $\mathrm{H}-$ bondsof the polysaccharide moieties, respectively. The occurrence of a broader band at $3419 \mathrm{~cm}^{-1}$ revealed morehydrophilic character of CMC as compared to the initial chitosan (Fig.2B). Therefore, carboxylation occurred on some of both the amino and the primary hydroxyl moieties of the glucosamine units of the chitosan structure (Miao et al., 2006) and we can conclude that structure is $\mathrm{N}, \mathrm{O}-\mathrm{CMC}$. The band at $2926 \mathrm{~cm}^{-1}$ could be assigned to $v(\mathrm{C}-\mathrm{H})$ from $\mathrm{CH}_{2}$ groups. The increase in width of the brands at $2960 \mathrm{~cm}^{-1}$ and $2930 \mathrm{~cm}^{-1}$ was assigned to $\mathrm{C}-\mathrm{H}$ stretching and asymmetric deformations in $\mathrm{CH}_{2}$. The asymmetric stretching vibration of the carboxylate group appears at $1620-1598 \mathrm{~cm}^{-1}$.

The introduction of carboxymethyl groups was confirmed by the occurrence of an intense band at $1589 \mathrm{~cm}^{-1}$ and a moderate band at $1409 \mathrm{~cm}^{-1}$. These bandswere attributed to symmetric and asymmetric deformationof $\mathrm{COO}^{-}$, respectively(Hua-Cai and Deng-Ke, 2005). A band at 1589 $\mathrm{cm}^{-1}$ was attributed to the angular deformation of the N-Hbonds of the amino group, which overlaps with $v_{a s}\left(\mathrm{COO}^{-}\right)$and $v_{s}\left(\mathrm{COO}^{-}\right)$. The new bands at $1413 \mathrm{~cm}^{-1}$ was observed in CMC FTIR spectra. Moreover, the bands at $1597-1650 \mathrm{~cm}^{-1}$ and $1414-1401 \mathrm{~cm}^{-1}$ corresponding to the carboxy group (which overlaps with $\mathrm{N}-\mathrm{H}$ bend) and $-\mathrm{CH}_{2} \mathrm{COOH}$ group respectively were intense in spectrum of CMC indicating carboxymethylation on both the amino and hydroxyl groups of chitosan. The bands in range 1417$1377 \mathrm{~cm}^{-1}$ were assigned with coupling of $\mathrm{C}-\mathrm{N}$ stretching and $\mathrm{N}-$ $\mathrm{H}$ angular deformation (Mourya et al., 2010). Additionally,the formation of $\mathrm{CMC}$ was also confirmedby the intensification of the band at 1067 and $1323 \mathrm{~cm}^{-1}$ corresponding to $v(\mathrm{C}-\mathrm{O}-\mathrm{C})$ and $v \mathrm{~s}(\mathrm{C}-\mathrm{OH})$. The stretching vibrations in the range of 1154-1029 $\mathrm{cm}^{-1}$ were assigned with glycosidic bonds, $\mathrm{C}-\mathrm{O}-\mathrm{C}$ and $\mathrm{C}-\mathrm{O}$ symmetric stretching vibrations stretchings from pyranose ring. The $\mathrm{C}-\mathrm{O}$ stretching band at $1028 \mathrm{~cm}^{-1}$ corresponding of the primary hydroxyl group disappears, verifying ahigh carboxymethylation of OH-6 (Zhang et al. 2000; Zhao et al., 2001; Meiling et al., 2011).In chitosan and CMC the bands at 989 and $943 \mathrm{~cm}^{-1}$ were attributed to the $\mathrm{C}-\mathrm{O}$ stretching vibration of pyranosyl ring and the $\mathrm{C}-\mathrm{O}$ stretching with contributions from $\mathrm{C}-$ $\mathrm{C}-\mathrm{H}$ and $\mathrm{C}-\mathrm{O}-\mathrm{H}$ deformation. In chitosan spectra band at $892 \mathrm{~cm}^{-}$ ${ }^{1}$ was due to $\mathrm{C}$-anomeric group stretching, $\mathrm{C}-1-\mathrm{H}$ deformations and pyranosyl ring stretching.

\section{${ }^{13}$ C NMR spectra}

Structure of chitosan and $\mathrm{CMC}$ were characterized by ${ }^{13} \mathrm{C}$ NMR spectroscopy.Chitosan ${ }^{13} \mathrm{C}$ NMR $\left(151 \mathrm{MHz}, \mathrm{CD}_{3} \mathrm{COOD}\right)$ chemical shifts were: $\delta$ 175.20, 99.42 (C-1), 78.07 (C-4), 74.71 (C-5), 72.50 (C-3), 69.69, 67.28, 66.59 (C-6), 54.54 (C-2), 13.89 ppm

${ }^{13} \mathrm{C}$ NMR spectra of chitosan consisted of eight welldefined resonances. Six signals in the range from 50 to $105 \mathrm{ppm}$ were due to carbon atoms from glucosamine pyranose ring. The single signal at $175.20 \mathrm{ppm}$ was assigned to the carbonyl carbons of carboxyl groups. The shifts at 13.89 ppm were due to $\underline{\mathbf{C H}}_{3}$ from acetyl residues. The reported chemical shifts in our study were consistent to the reported ones by Cárdenas et al. (2006).

CMC Chitosan ${ }^{13} \mathrm{C}$ NMR $(126 \mathrm{MHz}, \quad \mathrm{D} 2 \mathrm{O})$ 178.04,177.78, 175.94, 171.35, 101.51 (C-1), 78.40 (C-4), 77.98 (C-5), 73.89 (C-3), 70.29, 69.48, 61.19 (C-6), 60.02 (C-2), 57.41, $30.22,16.76 \mathrm{ppm}$.

The methylene groups $\left(-\mathrm{CH}_{2}\right)$ form carboxymethyl residues $\mathrm{O}_{\mathbf{C}} \mathrm{H}_{2} \mathrm{COOH}$ gave the signals at $57.41 \mathrm{ppm}$ and also in range between 67 and $74 \mathrm{ppm}$. The signal at $101.51 \mathrm{ppm}$ was typical for $\beta$ anomers in polysaccharide chain. Moreover, the signal observed at $178.04 \mathrm{ppm}$ was assigned to the carbonyl carbons of carboxymethyl groups. Chemical shifts at $177.78 \mathrm{ppm}$ corresponded to the carbonyl carbon of $-\mathrm{COCH}_{3}$ of the parent chitosan. The shifts at $175.94 \mathrm{ppm}$ can be assigned with $\mathrm{C}=\mathrm{O}$ substituted on $-\mathrm{OH}$. The presence of shifts at $170 \mathrm{ppm}$ and a weak 
signal at $57.41 \mathrm{ppm}$ proved that $-\mathrm{CH}_{2} \mathrm{COOH}$ was bonded to $-\mathrm{NH}_{2}$ groups of chitosan. The presence of chemical shifts at 70.29 and 69.48 ppm proved that substitution with $\mathrm{CH}_{2} \mathrm{COO}$ residues was occurred on O-6 and O-3 positions in pyranose units. The signal around $16.76 \mathrm{ppm}$, corresponding to $-\mathrm{CH}_{3}$ groups can be associated with presence of residual methanol used as a solvent for sample purification.

No significant differences between ${ }^{13} \mathrm{C}$ NMR spectra of chitosan and CMC presented in our study and the previously reported ones by some authors (Mourya et al., 2010; de Abreu and Campana-Filho, 2005).

\section{Thermal analysis of chitosan and CMC polymers}

The TGA and DTA curves of initial chitosan and carboxymethyl chitosan were shown (Fig.4 and Fig. 5).Chitosan (Fig.4) exhibited one-stage degradation behavior. The mass loss of $7.4 \%$ for chitosan was observed in the temperature range of 38 $132{ }^{\circ} \mathrm{C}$. That was associated with the endothermic peak due to loss of capillary bonded water. The thermogravimetric curve from TG analysis indicated the presence of an inflection point at $90{ }^{\circ} \mathrm{C}$ which showed a highly elastic state and could be considered as glass transition temperature. No degradation processes in chitosan thermogram were observed by $240{ }^{\circ} \mathrm{C}$ and that temperature could be defined as the limit of thermal stability of chitosan.

In CMC DTA thermogram (Fig. 5), the endothermic transition due to the evaporation of the capillary bounded water was observed at the same temperature of $36{ }^{\circ} \mathrm{C}$ and ended significantly faster at $102{ }^{\circ} \mathrm{C}$ with a peak at $76{ }^{\circ} \mathrm{C}$. The inflection point was at $75{ }^{\circ} \mathrm{C}$. Although the evaporation temperature range for was narrow, the released water was about $10 \%$ of tability of CMC the mass of the sample. The thermal was until $220^{\circ} \mathrm{C}$, after which exothermic transition was recorded beginning at $221^{\circ} \mathrm{C}$ and end at $259{ }^{\circ} \mathrm{C}$ with a maximum at $236{ }^{\circ} \mathrm{C}$. The onset of these pyrolytic degradation processes resulted from the decarboxylation of the acetate residues, whereby the mass lost was about $29 \%$. The similar observation was reported for other modified carbohydrate polymers (Murdzheva et al., 2016). After TGA/DTA analysis can be concluded that $\mathrm{CMC}$ is suitable to be used in heating and sterilization processes up to $220{ }^{\circ} \mathrm{C}$ without changing the quality composition.All these observations revealed the higher thermal stability of synthesized CMC for potential application in food processing and pharmaceutical preparations.

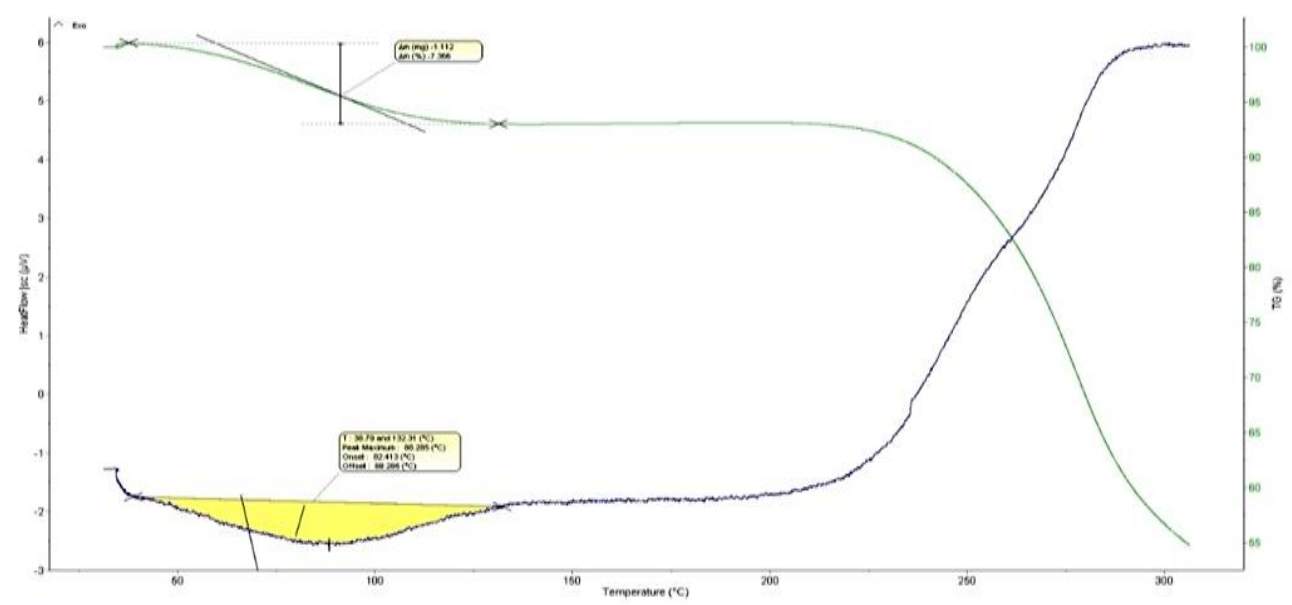

Fig. 4: TGA/DTA analyses of chitosan.

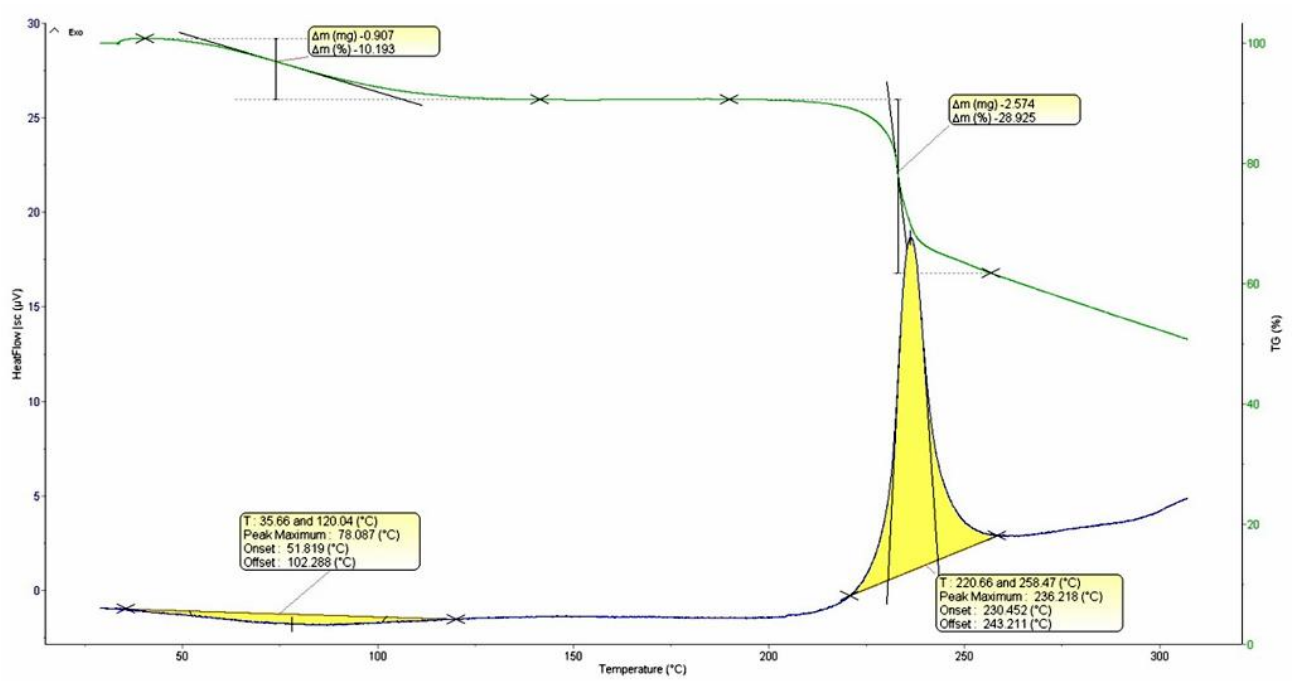

Fig. 5: TGA/DTA analyses of CMC. 


\section{Emulsions}

The synthesized CMC was incorporated in different concentration in oil/water emulsions. The resulting emulsions represented yellow-colored viscous mixtures with intense and typical rose odour and $\mathrm{pH}$ values measured in a range of 6.45 to 7.33. The results obtained by centrifugation showed that emulsions are stable in the range of $20-26$ months.

The microscopy images of emulsions 1, 2 and 3 after three days storage are shown (Fig. 6). An important parameter for emulsion stability is droplets size determination and their distribution in the continuous phase (McClements, 2005). The average radius of emulsion droplets has been calculated. The image of emulsion 1 showed a homogeneous structure with approximately equal droplets size $(\mathrm{r}=14.23 \mu \mathrm{m})$. The small particles size was associated with greater dispersion system stability. Microscopic images of emulsions 2 and 3 showed larger emulsion droplets $(38.73 \mu \mathrm{m}$ and $46.97 \mu \mathrm{m})$ compared to emulsion 1. But they were similarly stable and that was confirmed by the results obtained for thermodynamic parameters shown in Table 2. Thermodynamic parameters of emulsions have been calculated and their values were presented in Table 2.
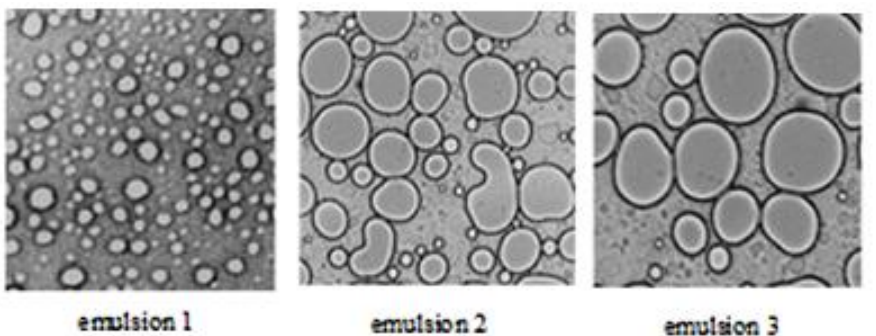

Fig. 6: Microscopy images of the structure of model oil/water emulsions.

Table 2: Thermodynamic parameters obtained in emulsions at $298.2 \mathrm{~K}$.

\begin{tabular}{ccccc}
\hline Emulsion & $\begin{array}{c}\Delta \mathbf{G} \\
{\left[\mathbf{k J ~ m o l}^{-\mathbf{1}}\right]}\end{array}$ & $\begin{array}{c}\Delta \mathbf{H} \\
{\left[\mathbf{k J ~ m o l}^{-\mathbf{1}}\right]}\end{array}$ & $\begin{array}{c}\mathbf{\Delta S} \\
{\left[\mathbf{k J ~ m o l}^{-\mathbf{1}} \mathbf{K}^{-\mathbf{1}}\right]}\end{array}$ & $\mathbf{K}$ \\
\hline 1 & $-11.3 \pm 0.4$ & $-22.2 \pm 0.6$ & $-0.0367 \pm 0.0012$ & $96.8 \pm 3.3$ \\
2 & $-10.7 \pm 0.4$ & $-22.0 \pm 0.6$ & $-0.0379 \pm 0.0012$ & $75.2 \pm 8.7$ \\
3 & $-10.6 \pm 0.5$ & $-21.9 \pm 0.7$ & $-0.0303 \pm 0.0010$ & $74.0 \pm 7.4$
\end{tabular}

The thermodynamic parameters (Gibbs free energy, enthalpy and entropy) and the equilibrium constant of the process were calculated by spectrophotometric method. They are indicators for system stability. The highest value of the constant was observed for emulsion 1, therefore it was evaluated as the most stable compared to another two. The value of equilibrium constants for emulsion 2 and 3 were approximately similar and they were similarly stable in thermodynamic terms.

The relationship between $\mathrm{K}$ and the energy of Gibbs was proportional. It was observed that $\Delta \mathrm{G}<0$ for the analyzed emulsions (Table 2). $\Delta \mathrm{G}$ was in the range of -10.6 and -11.3 $\mathrm{kJ} \mathrm{mol}^{-1}$. The same results in terms of stability were established by microscopic analysis (Fig. 6).

Calculated enthalpies of the three emulsions had relatively high negative values. It was connected with strong endothermic processes, which shifts the equilibrium towards the formation of the products (in this case - towards the stable emulsion formation).

Entropy in each emulsion system had low negative value close to zero and did not affect the direction of the process. This means that the system will long be regarded as an emulsion.

\section{Rheological behavior}

All tested emulsions (Table 3) behaved like HerschelBulkley visco-platic fluids, but they were also closed to the Bingham plastics (the flow index (n) had values above 0.5 - from 0.57 to 0.87 , with two exceptions). In the Bingham model flow index (n) is always equal to 1 .

The apparent viscosity $(\mu)$ decreased with increasing number of the emulsions. For emulsion 1 (control) it was in the range of 642 to $64.2 \mathrm{~Pa}$.s; for emulsion 2 with $0.5 \% \mathrm{CMC}$ - from 442.5 to $42.8 \mathrm{~Pa}$.s; for emulsion 3 with $0.3 \% \mathrm{CMC}$ - from 224.2 to 31.1 Pa.s (Fig. 7).

By increasing the temperature of each emulsions, viscosity and shear stress decreased with different gradient - the highest for emulsion $3-55.4 \%$ (for emulsion $1-35.8 \%$, for emulsion $2-49.0 \%$ ). The same case happened with a large shear rate - emulsion $3-42.9 \%$, emulsion $2-31.0 \%$ and emulsion $1-$ $21.8 \%$. The use of CMC as a thickening agent implies good knowledge of their rheological characteristics. The emulsions containing $0.5 \%$ and $0.3 \%$ CMC could be applied in pharmaceutical and cosmetic formulations.

Table 3: Rheological characteristics of emulsion systems.

\begin{tabular}{|c|c|c|c|c|c|c|c|c|c|c|c|c|}
\hline \multirow{3}{*}{ Emulsion } & \multicolumn{12}{|c|}{$\mathrm{D}=0.1-1.02 \mathrm{~s}^{-1}$} \\
\hline & \multicolumn{3}{|c|}{$\mathrm{t}=20^{\circ} \mathrm{C}$} & \multicolumn{3}{|c|}{$\mathrm{t}=25^{\circ} \mathrm{C}$} & \multicolumn{3}{|c|}{$\mathrm{t}=30^{\circ} \mathrm{C}$} & \multicolumn{3}{|c|}{$\mathrm{t}=35^{\circ} \mathrm{C}$} \\
\hline & $\begin{array}{l}\tau_{0} \\
\mathrm{~Pa}\end{array}$ & $\begin{array}{c}\mathrm{k} . \\
\mathrm{Pa} \cdot \mathrm{s}^{\mathrm{n}}\end{array}$ & $\mathrm{n}$ & $\tau_{0} . \mathrm{Pa}$ & $\begin{array}{c}\text { k. } \\
\text { Pa.s }\end{array}$ & $\mathrm{n}$ & $\tau_{0} . \mathrm{Pa}$ & $\begin{array}{c}\text { k. } \\
\text { Pa.s }{ }^{n}\end{array}$ & $\mathrm{n}$ & $\tau_{0} . \mathrm{Pa}$ & $\begin{array}{c}\text { k. } \\
\text { Pa.s }\end{array}$ & $\mathrm{n}$ \\
\hline 1 & 60.0 & 23.7 & 0.66 & 51.7 & 27.6 & 0.57 & 46.1 & 25.6 & 0.80 & 38.2 & 27.4 & 0.87 \\
\hline 2 & 39.5 & 23.9 & 0.65 & 31.6 & 28.8 & 0.77 & 16.6 & 36.9 & 0.66 & 10.7 & 33.6 & 0.47 \\
\hline 3 & 10.7 & 33.6 & 0.47 & 7.78 & 48.6 & 0.57 & 5.85 & 34.8 & 0.68 & 0.8 & 30.5 & 0.57 \\
\hline
\end{tabular}



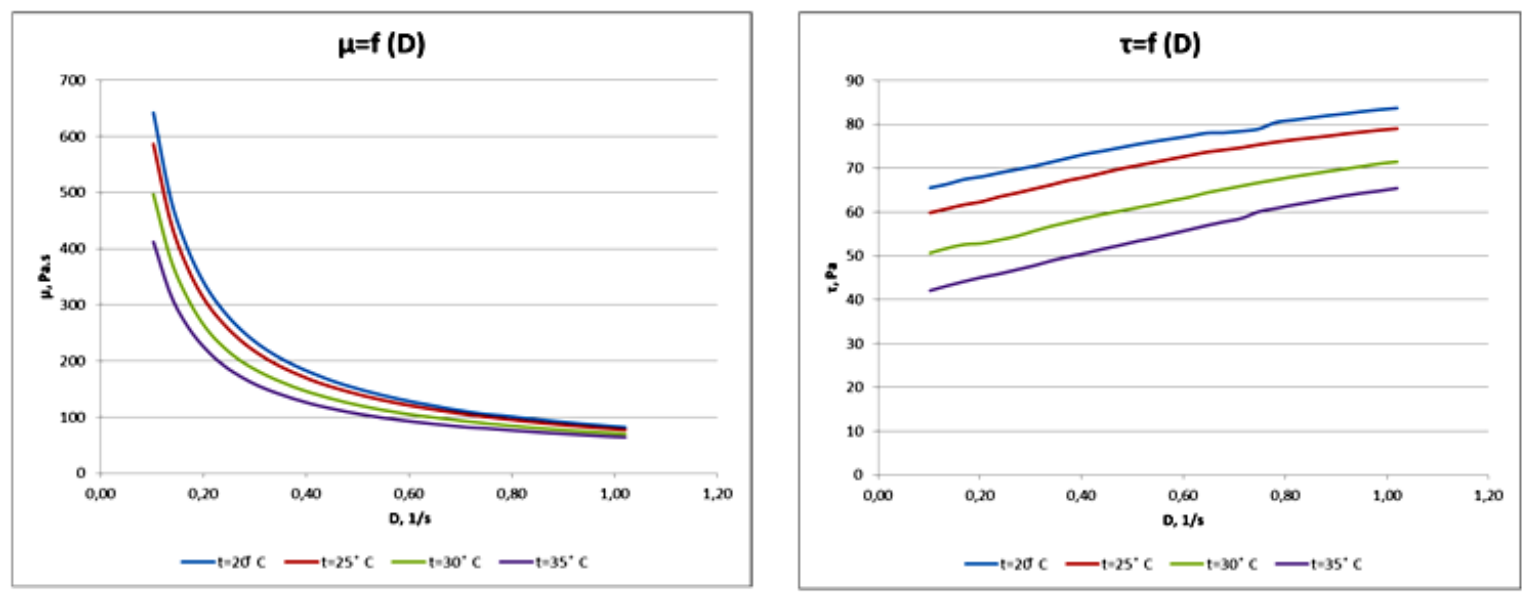

Emulsion 1 (control)
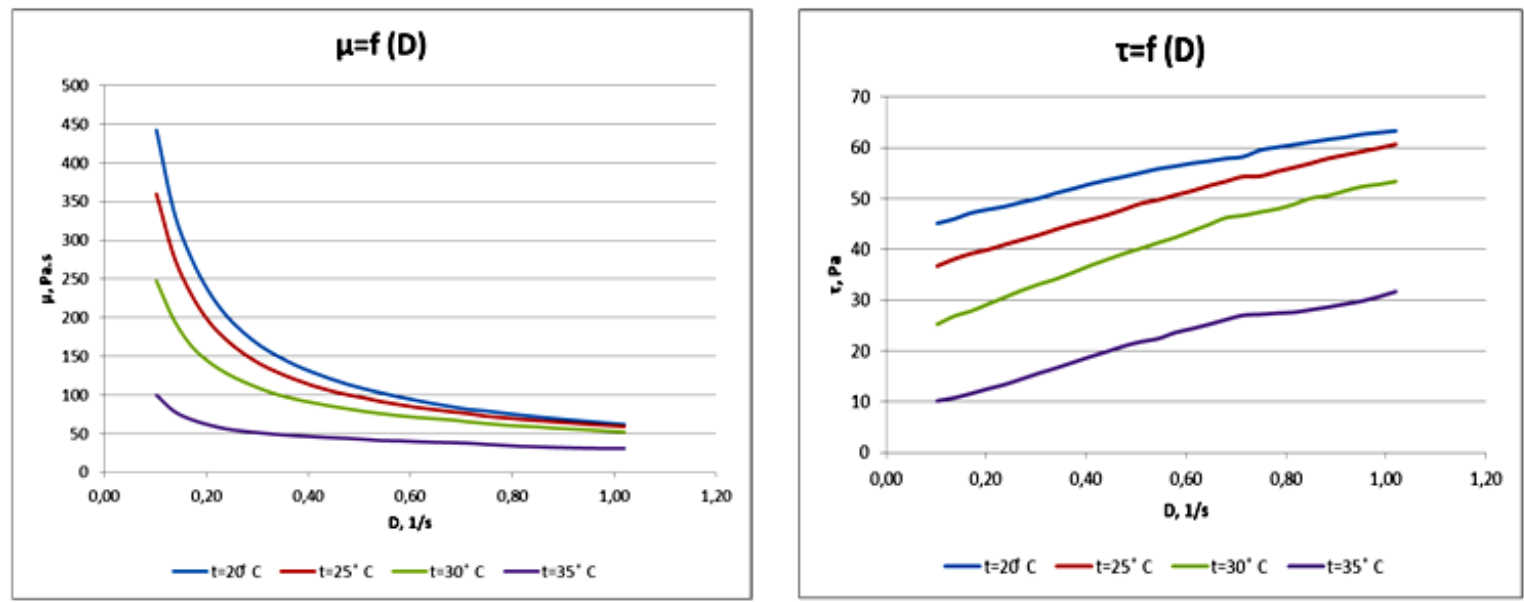

Emulsion 2
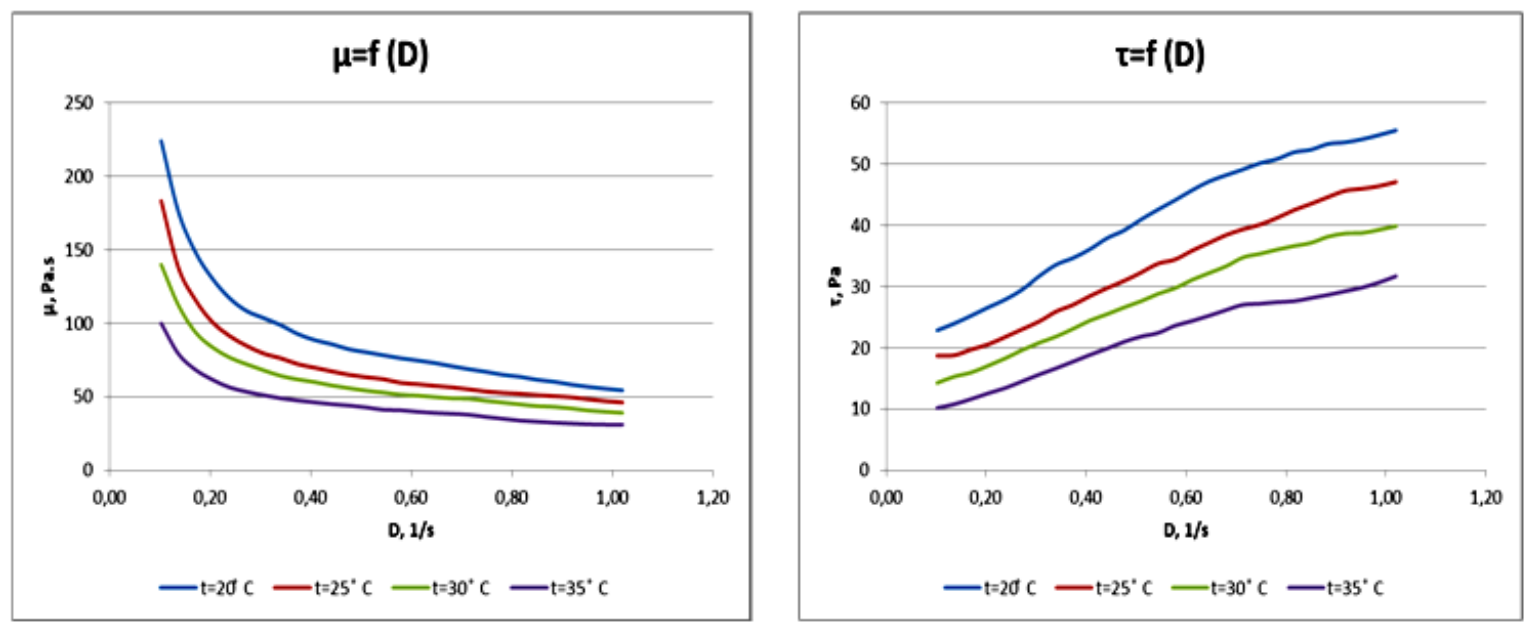

Emulsion 3

Fig. 7: Viscosity $(\mu)$ and shear stress $(\tau)$ of emulsions with CMC as a function of shear rate (D). 


\section{CONCLUSION}

Carboxymethyl chitosan with $50 \%$ degree of substitution was successfully synthesized. The resulting product was characterized by FTIR and NMR spectroscopy and TGA. Carboxymethylchitosan is water soluble polymer with high viscosity in resulting solutions and could be successfully used in pharmaceutics and cosmetics as emulsion stabilizer and thickening agent. The thermodynamic parameters of emulsions (Gibbs free energies, enthalpies and entropies) and rheological properties indicate that the carboxymethylchitosan synthesized by us can successfully replace the stabilizer Carbomer that has traditionally been used in pharmaceutical and cosmetic oil/water emulsions. Some important rheological parameters like creep recovery, spreadability and etc. will be an object for future investigations.

\section{Financial support and sponsorship: Nil.}

Conflict of Interests: There are no conflicts of interest.

\section{REFERENCES}

Ali Z, Laghari A, Ansari A, Khuhawar M. Synthesis and characterization of carboxymethyl chitosan and its effect on turbidity removal of river water. J. Appl. Chem. 2013; 5(3):72-79.

Bidgoli H, Zamani A, Taherzadeh M. Effect of carboxymethylation conditions on the water-binding capacity of chitosan-based superabsorbents. Carbohyd. Res. 2010; 345 (18):2683-2689.

Cárdenas G, Cabrera G, Taboada E, Rinaudo M. Synthesis and characterization of chitosan alkyl phosphate. J. Chil. Chem. Soc. 2006; 51(1):815-820.

Chen L, Du Y, Tian Z, Sun L. Effect of the degree of deacetylation and the substitution of carboxymethyl chitosan on its aggregation behavior. J. Polym. Sci. Polym. Phys. 2005; 43:296-305.

Chen X, Park H. Chemical characteristics of O-carboxymethyl chitosans related to the preparation conditions. Carbohyd. Polym. 2003; 53( 4):355-359.

Cochran S, Brockman T. A cosmetic ingredient innovation for the stabilization and delivery of volatile fluoroether with cosmetic applications. J. Cosmet. Sci. 2007; 58:413-419.

Cravotto G, Tagliapietra S, Robaldo B, Trotta M. Chemical modification of chitosan under high-intensity ultrasound. Ultrason. Sonochem. 2005; 12: 95-98

de Abreu F, Campana-Filho S. Preparation and characterization of carboxymethylchitosan. Polímeros: Ciência e Tecnologia 2005; 15(2):79-83.

Ewing G. 1969. Instrumental methods of chemical analysis. New York, McGraw-Hill.

Gandova V,Balev D. Properties of emulsions based in soybean oil stabilized by different proteins. Int. J. Inn. Sci. Eng. Technol. 2016; 3(5):293297.

Holme K, Perlin A. Chitosan N-sulfate. A water-soluble polyelectrolyte. Carbohydr Res. 1997; 302(1-2):7-12.

Hua-Cai G, Deng-Ke L. Preparation of carboxymethyl chitosan in aqueous solution under microwave irradiation. Carbohyd. Res. 2005; 340:1351-1356.

Jia Z, Shen D, Xu W. Synthesis and antibacterial activities of quaternary ammonium salt of chitosan. Carbohydr. Res. 2001; 333(1):1-6.

Jimtaisong A, Seawan N. Utilization of carboxymethyl chitosan in cosmetics. Int. J. Cosmet. Sci. 2014; 36:12-21.

Jung B, Kim C, Chio K, Lee Y, Kim J. Preparation of amphiphilic chitosan and their antimicrobial activities. J. Appl. Polym. Sci. 1999; 72 (13): 1713-1719.

Kasaai M, Arul J, Charlet G. Fragmentation of chitosan by acids. The Scientific World Journal 2013: 1-11.

Kim S, Shin S, Lee Y, Kim S. Swelling characterizations of chitosan and polyacrylonitrile semi-interpenetrating polymer network hydrogels. J. Appl. Polym. Sci. 2003; 87:2011-2015.
Kurita K. Controlled functionalization of the polysaccharide chitin, Progress in Polymer Science 2001; 26:1921-1971.

Lee S, Liu K, Liu Y, Chang Y, Lin C, Chen Y. Chitosonic $®$ acid as a novel cosmetic ingredient: Evaluation of its antimicrobial, antioxidant and hydration activities. Materials 2013; 6:1391-1402.

Lei CX, Hu SQ, Shen GL, Yu RQ. Immobilization of horseradish peroxidase to a nano-Au monolayer modified chitosan-entrapped carbon paste electrode for the detection of hydrogen peroxide. Talanta 2003; 59:981-993.

McClements D. 2005. Food emulsions: principles, practice and techniques, 2nd edition, Boca Raton: CRC Press

Meiling Z, Baoqin H, Yan Y, Wanshun L. Synthesis, characterization and biological safety of O-carboxymethyl chitosan used to treat Sarcoma 180 tumor. Carbohyd. Polym. 2011; 86:231-238.

Miao J, Chen G, Gao C, Lin C, Wang D, Sun M. Preparation and characterization of N, O-carboxymethyl chitosan (NOCC)/polysulfone (PS) composite nanofiltration membranes. J. Membrane Sci. 2006; 280:478-484.

Mourya V, Inamdar N. Trimethyl chitosan and its applications in drug delivery. J. Mater. Sci. Mater. Med. 2009; 20:1057-1079.

Mourya V, Inamdar N., Tiwari A. Carboxymethyl chitosan and its applications. Advanced Materials Letters 2010; 1(1):11-33.

Mourya VK, Inamdar NN.Chitosan-modifications and applications: opportunities galore. React. Funct. Polym. 2008; 68(6):1013-1051.

Murdzheva D, Petkova N, Todorova M, Vasileva I, Ivanov I, Denev P. Microwave-assisted synthesis of methyl esters of alginic acids as potential drug carrier. Int. J. Pharmac. Clinical Res. 2016; 8(10):1361-1368.

Muzzarelli R. Carboxymethylated chitins and chitosans. Carbohyd.Polym.1988; 8:1-21.

Ouchi T, Nishizawa H, Ohya Y. Aggregation phenomenon of PEGgrafted chitosan in aqueous solution. Polymer 1998; 39:5171-5175.

Park IK, Kim TH, Kweon HY, Park YH, Kim WJ, Akaike T, Cho CS. Visualization of transfection of galactosylated chitosan-graft-poly(ethylene glycol) /DNA complexes into hepatocytes by confocal laser scanning microscopy. Int. J. Pharm. 2003; 257:103-110.

Patravale V, Mandawgade S. Novel cosmetic delivery systems: An application update. Int. J. Cosmet. Sci. 2008; 30:19-33.

Sashiwa H, Kawasaki N, Nakayama A, Muraki E, Yajima H, Yamamori N, Ichinose Y, Sunamoto J, Aiba S. Chemical modification of chitosan. Synthesis of novel chitosan derivatives by substitution of hydrophilic amine using $\mathrm{N}$-carboxyethylchitosan ethyl ester as an intermediate. Carbohydr. Res. 2003; 338(6):557-561.

Shanmuganathan S, Nigma Chandra S, Anbarasan B, Harika B. Preparation and in-vitroevaluation of $\mathrm{Fe}_{3} \mathrm{O}_{4}$ encapsulated by chitosan loaded capecitabine nanoparticles for the treatment of breast cancer. J. Drug Delivery Techn. 2016; 6(3):52-57.

Sharma D., Dhanjal D. S., Mittal B. Development of Edible Biofilm Containing Cinnamon to Control Food-Borne Pathogen. Journal of Applied Pharmaceutical Science 2017; 7 (01): 160-164

Tcholakova S., N. Denkov, I. Ivanov, R. Marinov. Evaluation of Short-Term and Long-Term Stability of Emulsions by centrifugation and NMR. Bulg. J.Phys. 2004; 31: 96-100.

Yalpani M, Marchessauh R, Morin F, Monasterios C. Synthesis of poly(3-hydroxyalkanoate) (PHA) conjugates: PHA-carbohydrate and PHAsynthetic polymer conjugates . J. Macromolecules 1991; 24:6046-6049.

Yang C, Chen Y, Lai J, Hong W, Lin C. Determination of the thermodegradation of deoxyarbutin in aqueous solution by high performance liquid chromatography. Int. J. Mol. Sci. 2011; 11:3977-3987.

Zhang L, Guo J, Zhou J, Yang G, Du Y. Blend membranes from carboxymethylated chitosan/alginate in aqueous solution. J. Appl.Polym. Sci. 2000; 77(3):610-616.

Zhao X, Kato K, Fukumoto Y, Nakamae K. Synthesis of bioadhesive hydrogels from chitin derivatives. Int. J. Adhesion and Adhesives. 2001; 21(3): 227-232.

\section{How to cite this article:}

Tzaneva D, Simitchiev A, Petkova N, Nenov V, Stoyanova A, Denev P. Synthesis of Carboxymethyl Chitosan and its Rheological Behaviour in Pharmaceutical and Cosmetic Emulsions. J App Pharm Sci, 2017; 7 (10): 070-078. 